\title{
Arsenic exposure and risk of nonalcoholic fatty liver disease (NAFLD) among U.S. adolescents and adults: an association modified by race/ethnicity, NHANES 2005- 2014
}

Jennifer K. Frediani ${ }^{1}$, Eric A. Naioti ${ }^{2}$, Miriam B. Vos ${ }^{1}$, Janet Figueroa ${ }^{1}$, Carmen J. Marsit ${ }^{3}$ and Jean A. Welsh ${ }^{1,4^{*}}$

\begin{abstract}
Background: While associated with obesity, the cause of the rapid rise in prevalence of nonalcoholic fatty liver disease (NAFLD) in children, which is highest among Hispanics, is not well understood. Animal experiments have demonstrated that arsenic exposure contributes to liver injury. Our objective was to examine the association between arsenic exposure and NAFLD in humans and to determine if race/ethnicity modifies the association.

Methods: Urinary inorganic arsenic concentrations among those $\geq 12$ years in the National Health and Nutrition Examination Survey, 2005-2014 were used to assess the cross-sectional association with serum alanine aminotransferase (ALT) levels, a marker of liver dysfunction. We excluded high alcohol consumers ( $>4-5$ drinks/day; $n=939$ ), positive hepatitis B or C $(n=2330)$, those missing body mass index $(n=100)$ and pregnant women $(n=629)$ for a final sample of 8518. Arsenic was measured using liquid chromatography coupled with mass spectrometry and ALT was measured using standard methods. Sampling weights were used to obtain national estimates. Due to lack of normality, estimates were log transformed and are presented as geometric means. Logistic regression models controlling for age, sex, income, and weight category estimate adjusted odd ratios (aOR) of elevated ALT by quartile of arsenic and tested for effect modification by race/ethnicity and weight. Elevated ALT was defined as $>25 \mathrm{IU} / \mathrm{L}$ and $>22 \mathrm{IU} / \mathrm{L}$ for boys and girls $\leq 17$ years, respectively and $>30 \mathrm{IU} / \mathrm{L}$ and $>19 \mathrm{IU} / \mathrm{L}$ for men and women, respectively.

Results: Among all, aOR of elevated ALT were higher among those in the highest vs. lowest arsenic quartile (referent), 1.4 (95\% confidence interval $[\mathrm{Cl}]$ : 1.1, 1.7) with a borderline significant interaction $(p=0.07)$ by race/ ethnicity but not weight $(p=0.4)$. In analysis stratified by race/ethnicity, aOR of elevated ALT among those in the 4th quartile were higher among Mexican Americans, 2.0 (Cl: 1.3, 3.1) and non-Hispanic whites only, aOR 1. 4 (Cl: $1.1,1.8)$ despite the fact that obesity prevalence was highest among non-Hispanic blacks.

Conclusions: Our findings demonstrate a positive association between urinary arsenic exposure and risk of NAFLD among U.S. adolescents and adults that is highest among Mexican Americans and among those obese, regardless of race/ethnicity.
\end{abstract}

Keywords: Nonalcoholic fatty liver disease (NAFLD), Arsenic, Obesity, NHANES, Hispanic, Alanine aminotransferase

\footnotetext{
* Correspondence: jean.a.welsh@emory.edu

${ }^{1}$ Department of Pediatrics, Emory University School of Medicine, Atlanta, GA,

USA

${ }^{4}$ Wellness Department, Children's Healthcare of Atlanta, Atlanta, GA, USA

Full list of author information is available at the end of the article
} 


\section{Background}

The prevalence of nonalcoholic fatty liver disease (NAFLD), which is characterized by an accumulation of fat in the liver, has risen markedly in the U.S. over recent decades [1]. Currently prevalence is estimated to be $30 \%$ among adults in the U.S. [2] with rates highest among males and among Hispanic Americans, specifically Mexican Americans [1,3]. Described as the liver manifestation of metabolic syndrome, NAFLD can progress to include liver inflammation and fibrosis and increase risk of liver cancer [4]. While NAFLD occurs primarily in the presence of obesity, its cause is unknown. The genetic variant, PNPLA3, which is common among Hispanics, has been associated with alanine aminotransferase (ALT) levels, a marker of liver damage, and increased hepatic fat [5-7]. Recent evidence suggests that exposure to environmental pollutants including those that are inhalation and ingestion toxicants [8-10], including heavy metals such as arsenic [11], may play a role. Lin et al. previously found a significant association between several soil-derived heavy metals, including arsenic, and NAFLD in lean Tiawanese men, but the independent effect of arsenic was not examined [11].

Arsenic is present in the environment in both organic and inorganic form. Exposure to the inorganic forms (iAs), arsenite and arsenate, is known to be carcinogenic, atherogenic, neuropathogenic. At low doses, iAs has also been shown to diminish insulin sensitivity in both children and adults and to induce diabetes in animals and humans [12-14]. Adults with trace increases in urinary iAs have $50 \%$ greater risk of type 2 diabetes [15]. When iAs concentrations in drinking water are low $(<10 \mu \mathrm{g} / \mathrm{L})$, such as in the U.S., where they are regulated in public water supplies, foods such as rice, other cereals and cereal products, infant rice-based cereals and poultry are the major contributors. [16-18] iAs contamination in rice results from soil contamination. The rice plant extracts iAs from the soil and concentrates it in the grain. Previously iAs was also found in poultry due to the use of arsenic-based drugs to prevent histomoniasis in U.S. produced chicken and turkey. This practice was discontinued in 2016 [19]. Notably, urinary iAs concentrations in the U.S. are increased in Asians and Hispanics compared to non-Hispanic whites, presumably because of cultural dietary differences [20-22]. In U.S. children, for every $1 / 4$ cup per day increase in rice consumption, urinary arsenic concentrations increased by $14 \%$ (CI 14-17\%) [23].

In murine models, iAs invokes various changes to hepatic tissue at relatively low doses. It has been shown to change the vascularization of the liver tissue [24] and gene expression within hepatic transporters [25]. Tan and colleagues fed male C57BI/6 J mice either a high fat or low fat diet and exposed them to arsenic through drinking water. While the low fat diet mice did not have increased liver damage, the combination of high fat diet and iAs produced the highest degree of liver damage and inflammation [26]. These changes in conjunction with other risk factors such as obesity suggests that low dose iAs could play an important role in NAFLD.

Due to the known dysmetabolic effect of iAs exposure, we aimed to use data from a national sample to assess its association with NAFLD risk and to determine if this exposure may help to explain the race/ethnic differences in risk that have been observed. We hypothesized that greater exposure to arsenic may be contributing to the higher prevalence of NAFLD among Hispanics.

\section{Methods \\ Study population}

Data from the National Health and Nutrition Examination Survey (NHANES) was used in this study. NHANES is a cross-sectional survey with a complex, multi-stage, probability sampling design. Ten years of data across five NHANES cycles (2005/2006 through 2013/2014) were examined. In NHANES, arsenic exposure, through urinary metabolite analysis, was assessed in participants aged 12 years and older. We excluded from the sample participants with hepatitis B or C $(n=2330)$ and those with high alcohol consumption ( $>4-5$ drinks/day; $n=939$ ) given that these conditions can cause liver damage and raise ALT levels. We excluded those missing body mass index (BMI) data $(n=100)$ and those pregnant $(n=629)$ leaving a final sample of 8516 . We created a separate category $(n=647)$ for those with missing poverty income ratio (PIR) but maintained them in the sample.

\section{Arsenic exposure}

Urine samples were collected in arsenic free containers and were analyzed for total urinary arsenic concentrations. These measurements reflect approximately the last 3 days of exposure [27, 28]. Inductively coupled-plasma dynamic reaction cell-mass spectrometry (ICP-DRC-MS) was used to measure total arsenic and speciated arsenic, including arsenobetaine and arsenocholine, which are arsenosugars and are considered non-toxic [29]. The lower limit of detection (LLOD) for arsenobetaine was $0.4 \mu \mathrm{g} / \mathrm{L}$ for 2005 through 2010, $1.19 \mu \mathrm{g} / \mathrm{L}$ in 2011/2012, and $1.16 \mu \mathrm{g} / \mathrm{L}$ in $2013 / 2014$. For arsenocholine, the LLOD was $0.6 \mu \mathrm{g} / \mathrm{L}$ for 2005 through $2010,0.28 \mu \mathrm{g} / \mathrm{L}$ in $2011 / 2012,0.11 \mu \mathrm{g} / \mathrm{L}$ in $2013 / 2014$. For total arsenic and speciated arsenics, samples that were below the LLOD ( $n=90$ samples) were assigned a value of LLOD divided by the square root of two [30]. From total arsenic measures, total inorganic arsenic concentrations were estimated by subtracting measurements for arsenobetaine and arsenocholine. Due to measurement error, some estimates for arsenic $(n=105)$ were below zero $(\mu \mathrm{g} / \mathrm{L})$; therefore, any value below $0.01(\mu \mathrm{g} / \mathrm{L})$ was replaced by 0.01 [31]. Arsenic concentrations were corrected for 
urine dilution using a covariate-adjusted standardization of arsenic concentration divided by creatinine concentration to control for measurement error bias caused by urinary diluteness [31]. Urine samples were analyzed on a Beckman CX3 using the Jaffe reaction to quantify creatinine concentrations in the 2005/2006 cycle. From 2007 through 2014 creatinine was measured on a Roche ModP Chemistry Analyzer using an enzymatic method. Measurements for creatinine corrected iAs were stratified into quartiles based on estimates of population quartiles of $2.42,4.08$, and $6.99(\mu \mathrm{g} / \mathrm{L})$ for the first quartile, median, and third quartile respectively.

\section{NAFLD assessment}

ALT, a liver enzyme often elevated in the presence of liver disease is commonly used as a screening test and monitoring biomarker for NAFLD [32-34]. Individuals age 12 years and older participating in NHANES had fasting blood samples taken at a mobile examination center. Serum ALT concentrations (U/L) were measured either on a Beckman Synchron LX20 (2005/2006) using an enzymatic rate method, or on a Beckman UniCel DxC800 Synchron (2007 through 2014) using a kinetic rate method. ALT was dichotomized use cut-offs commonly used clinically: high ALT was defined as $>25$ IU/L for boys $\leq 17$ years and $>22$ IU/L for girls $\leq 17$ years [32]. In adults, high ALT was defined as $>30$ IU/L in males and $>19$ IU/L in females [35].

\section{Other covariates}

Demographic variables of age (in years), sex, race/ethnicity and household income, were collected via interviewer assisted interviews. The poverty-to-income ratio (PIR) was calculated as the annual household income divided by the poverty threshold determined annually by the U.S. Department of Health and Human Services and grouped into three categories: $<130,130-350,>350 \%$ for analysis [36]. Participants' height and weight were measured at the NHANES mobile examination center. BMI was calculated as weight $(\mathrm{kg}) /$ height $\left(\mathrm{m}^{2}\right)$ and used to group study participants as underweight $(<18.5)$, normal weight $(18.5-<25)$, overweight $(25-<30)$ and obese $(\geq 30)$.

Hepatitis $B$ and $C$ positive participants were defined as those testing positive for the hepatitis $\mathrm{B}$ core antibody (Anti-HBc) or hepatitis C antibody (Anti-HCV). The VITROS Anti-HBc and Anti-HCV assays were performed using the VITROS Anti-HBc or Anti-HCV Reagent Pack and the VITROS Immunodiagnostic Products Anti-HBc or Anti-HCV calibrator on the VITROS ECi/ECiQ or VITROS 3600 Immunodiagnostic System. Hepatitis C antibody data was not provided for the NHANES cycle from 2013 to 2014, therefore no participants were excluded from this cycle for having hepatitis $\mathrm{C}$.

\section{Statistical analysis}

Descriptive analyses and regression model fitting were conducted using methods that accounted for the complex survey design of NHANES. Since multiple cycles were used, weights were adjusted by dividing by the number of cycles in each weighted analysis. The distribution of iAs was right skewed and therefore log-transformed. ANOVA and post-hoc $t$-tests were used for comparisons between variables of interest. Geometric means were presented. (Tables 2 and 3) As the relationship between the logtransformed iAs and elevated ALT levels was not linear for some race/ethnic groups, iAs concentrations were analyzed in quartiles. Logistic regression was used to estimate adjusted odds ratios (aORs) of elevated ALT adjusting for age, ethnicity, sex, weight category, and PIR (Table 4) with increasing iAs concentrations (in quartiles) stratified by race/ethnicity and weight category. Survey year was also included as a categorical variable in the models to adjust for any temporal changes between survey cycles. This analysis was also repeated among those obese only and stratified by race/ethnicity. We assessed for interactions of weight status (categorized) and of race/ethnicity with quartiles of arsenic exposure by including multiplicative interaction terms in the full models.

SAS 9.4 (SAS Institute Inc., Cary, NC) was used for all analysis. A $p$-value of 0.05 was used to determine statistical significance. Sampling weights were applied to all analyses to obtain nationally representative estimates. A sensitivity analysis was done using unweighted data to confirm the stability of the weighted estimates.

\section{Results}

The sample-weighted median age was 38 (interquartile range $[\mathrm{IQR}] 20,58)$ years. Most were non-Hispanic white (42\%) followed by non-Hispanic black (21\%), MexicanAmerican (19\%), other Hispanics (9\%) and other/mixed (8\%) (Table 1). Obesity prevalence was significantly higher among non-Hispanic blacks and significantly lower among the other/mixed race group compared to all other race/ ethnic groups (not shown). Geometric mean ALT was $21.5 \mathrm{U} / \mathrm{L}(21.2,21.8)$ with concentrations significantly higher among adults, males, Mexican Americans, other Hispanics, or non-Hispanic whites, higher income, and those overweight or obese. (Table 2) The geometric mean iAs was $3.8 \mathrm{mcg} / \mathrm{L}(3.5,4.1)$ with concentrations higher among adults, males, other Hispanics and other/mixed race (Table 3). There were no significant differences in iAs by income level or weight category.

In the full model, the odds of elevated ALT adjusted for age, sex, PIR, weight status, race/ethnicity and survey cycle rose with increasing arsenic exposure, from an aOR of 1.2 (95\% confidence interval [CI]: $0.7,1.9)$ for those in the second compared to the referent (first quartile of arsenic exposure), to an aOR of 2.0 (CI: 1.2, 3.4) 
Table 1 Characteristics of NHANES 2005-2014 unweighted sample

\begin{tabular}{ll}
\hline $\begin{array}{l}\text { Characteristics } \\
(n=8518)\end{array}$ & Value \\
\hline Age (years) [median(Q1,Q3)] & $38(20,58)$ \\
Female Gender $[n(\%)]$ & $4524(53.1)$ \\
Ethnicity $[n(\%)]$ & \\
$\quad$ Non-Hispanic White & $3579(42.0)$ \\
$\quad$ Non-Hispanic Black & $1828(21.5)$ \\
Mexican American & $1624(19.1)$ \\
Other Hispanic & $770(9.0)$ \\
Other/Mixed & $717(8.4)$ \\
Weight Status $[n(\%)]$ & \\
$\quad$ Normal or underweight & $3319(39.0)$ \\
(BMl $\left.<25.9 \mathrm{~kg} / \mathrm{m}^{2}\right)$ & \\
Overweight $\left(\mathrm{BMl} 25.9-29.9 \mathrm{~kg} / \mathrm{m}^{2}\right)$ & $2480(29.1)$ \\
Obese $\left(\mathrm{BMl}>30 \mathrm{~kg} / \mathrm{m}^{2}\right)$ & $2719(31.9)$ \\
PIR Status $[n(\%)]$ & \\
$<1.3$ & $2607(21.6)$ \\
$1.3-<3.5$ & $2852(34.8)$ \\
$\geq 3.5$ & $2412(43.6)$ \\
Missing & 647 \\
\hline
\end{tabular}

for those in the fourth quartile (Table 4). As testing for modification of this effect by race/ethnicity was borderline significant (F-test, $p=0.07$ ), further analysis was stratified and presented for each race/ethnic group separately. aORs were highest among Mexican Americans with risk of elevated ALT, compared to the referent, rising $50 \%$ among those in the second quartile of urinary iAs concentrations [1.5 (CI: 0.95, 2.2)], 70\% among those in the third quartile [1.7(CI: 1.1, 2.6)] and doubling among those in the fourth quartile $[2.0(1.3,3.1)]$ (Table 4). Increased odds among non-Hispanic whites were also observed but only among those in the 4th quartile of iAs exposure. There was no indication of an increase in risk among "other Hispanics" (Table 4).

Though the interaction term for weight status by iAS was not significant $(p=0.4)$, we repeated the analysis stratified by weight category to account for the unequal distribution of obesity across the race/ethnic groups. Here the odds of elevated ALT were greater for all weight categories when iAs was highest but among those obese a threshold affect was observed with risk rising $40 \%$ at the 2nd quartile of exposure and remaining at approximately the same level through the 4th quartile. Among those obese only, increased risk of elevated ALT was observed, though not always statistically significant, in the highest iAs exposure category among all the race/ethnic groups except for the "other/ mixed" race/ethnic group. The results of the sensitivity
Table 2 Geometric mean alanine aminotransferase (ALT) levels by demographic and weight status subgroups

\begin{tabular}{|c|c|c|c|c|c|}
\hline Covariate & $N$ & Mean, IU/L & \multicolumn{2}{|c|}{$\begin{array}{l}95 \% \mathrm{Cl} \text { for } \\
\text { Mean }\end{array}$} & $p$-value ${ }^{*}$ \\
\hline \multicolumn{6}{|l|}{ Age } \\
\hline$\leq 19$ years & 2063 & 17.7 & 17.2 & 18.3 & $p<0.0001$ \\
\hline$\geq 20$ years & 6455 & 22.2 & 21.9 & 22.6 & \\
\hline \multicolumn{6}{|l|}{ Gender } \\
\hline Male & 3994 & 25.1 & 24.6 & 25.7 & $p<0.0001$ \\
\hline Female & 4524 & 18.9 & 18.6 & 19.2 & \\
\hline \multicolumn{6}{|l|}{ Race/Ethnicity } \\
\hline Non-Hispanic White & 3579 & $21.5^{\mathrm{ab}}$ & 21.1 & 21.9 & $p<0.0001$ \\
\hline Non-Hispanic Black & 1828 & $19.2^{c}$ & 18.8 & 19.7 & \\
\hline Mexican-American & 1624 & $23.8^{\mathrm{a}}$ & 23.0 & 24.5 & \\
\hline Other Hispanic & 770 & $23.8^{\mathrm{abc}}$ & 22.8 & 24.1 & \\
\hline Other or Mixed & 717 & $21.5^{\mathrm{bc}}$ & 20.6 & 22.5 & \\
\hline \multicolumn{6}{|l|}{ Weight Status [n (\%)] } \\
\hline $\begin{array}{l}\text { Normal or underweight } \\
\left(\mathrm{BMl}<25.9 \mathrm{~kg} / \mathrm{m}^{2}\right)\end{array}$ & 3319 & $18.5^{\mathrm{a}}$ & 18.2 & 18.9 & $p<0.0001$ \\
\hline $\begin{array}{l}\text { Overweight } \\
\text { (BMI } 25.9-29.9 \text { kg/m²) }\end{array}$ & 2480 & $22.6^{\mathrm{b}}$ & 22.1 & 23.1 & \\
\hline $\begin{array}{l}\text { Obese } \\
\left(\text { BMI }>30 \mathrm{~kg} / \mathrm{m}^{2}\right)\end{array}$ & 2719 & $24.6^{\mathrm{b}}$ & 24.0 & 25.2 & \\
\hline \multicolumn{6}{|l|}{ PIR Status [n (\%)] } \\
\hline$<1.3$ & 2607 & $20.4^{\mathrm{ab}}$ & 19.9 & 20.9 & $p=0.02$ \\
\hline $1.3-<3.5$ & 2852 & $21.1^{\mathrm{a}}$ & 20.6 & 21.5 & \\
\hline$\geq 3.5$ & 2412 & $22.5^{\mathrm{b}}$ & 21.9 & 23.0 & \\
\hline Missing & 647 & $21.5^{\mathrm{ab}}$ & 20.7 & 22.4 & \\
\hline
\end{tabular}

${ }^{\circ} P$-value from ANOVA or $t$-tests

Note: means with same superscript letter are not significantly different

analyses using unweighted data were very similar to those obtained using data with sampling weights applied (not shown).

\section{Discussion}

The results of our study, the first such study among humans, demonstrates an association between arsenic exposure and risk of NAFLD among U.S. adolescents and adults, an association that our results suggest varies by race/ethnicity. There was a dose-response increase in risk among Mexican Americans and an elevated risk among non-Hispanic whites with the greatest arsenic exposure, but there was no significant increase in risk among other race/ethnic groups when examining the full sample. Our stratified analysis demonstrated that risk of elevated ALT is present with high iAs exposure, regardless of an individual's weight category, but risk occurs at lower levels of exposure among those obese. When examining this association among those obese only, we observed an increased risk at the highest quartile of iAs exposure 
Table 3 Geometric mean inorganic arsenic concentrations by demographic and weight status subgroups

\begin{tabular}{|c|c|c|c|c|c|}
\hline Covariate & $N$ & Mean, $\mu \mathrm{g} / \mathrm{L}$ & \multicolumn{2}{|c|}{$\begin{array}{l}95 \% \mathrm{Cl} \\
\text { for Mean }\end{array}$} & $p$-value ${ }^{*}$ \\
\hline \multicolumn{6}{|l|}{ Age } \\
\hline$\leq 19$ years & 2063 & 3.4 & 3.1 & 3.8 & $p=0.03$ \\
\hline$\geq 20$ years & 6455 & 3.9 & 3.6 & 4.2 & \\
\hline \multicolumn{6}{|l|}{ Gender } \\
\hline Male & 3994 & 4.4 & 4.1 & 4.8 & $p<0.0001$ \\
\hline Female & 4524 & 3.3 & 3.1 & 3.6 & \\
\hline \multicolumn{6}{|l|}{ Race/Ethnicity } \\
\hline Non-Hispanic White & 3579 & $3.3^{c}$ & 3.0 & 3.6 & $p<0.0001$ \\
\hline Non-Hispanic Black & 1828 & $5.0^{\mathrm{ab}}$ & 4.6 & 5.4 & \\
\hline Mexican-American & 1624 & $4.7^{\mathrm{a}}$ & 4.3 & 5.2 & \\
\hline Other Hispanic & 770 & $5.7^{b}$ & 5.0 & 6.4 & \\
\hline Other or Mixed & 717 & $5.6^{\mathrm{ab}}$ & 4.7 & 6.6 & \\
\hline \multicolumn{6}{|l|}{ Weight Status [n (\%)] } \\
\hline $\begin{array}{l}\text { Normal or underweight } \\
\left(\mathrm{BMI}<25.9 \mathrm{~kg} / \mathrm{m}^{2}\right)\end{array}$ & 3319 & 3.7 & 3.4 & 4.0 & $p=0.47$ \\
\hline $\begin{array}{l}\text { Overweight } \\
\left(\text { BMl } 25.9-29.9 \mathrm{~kg} / \mathrm{m}^{2}\right)\end{array}$ & 2480 & 3.9 & 3.5 & 4.3 & \\
\hline $\begin{array}{l}\text { Obese } \\
\left(\mathrm{BMI} \geq 30 \mathrm{~kg} / \mathrm{m}^{2}\right)\end{array}$ & 2719 & 3.9 & 3.5 & 4.3 & \\
\hline \multicolumn{6}{|l|}{ PIR Status } \\
\hline$<1.3$ & 2607 & 3.7 & 3.5 & 4.0 & $p=0.09$ \\
\hline $1.3-<3.5$ & 2852 & 3.6 & 3.3 & 3.9 & \\
\hline$\geq 3.5$ & 2412 & 4.0 & 3.6 & 4.4 & \\
\hline Missing & 647 & 4.2 & 3.5 & 5.1 & \\
\hline
\end{tabular}

${ }^{*} P$-value from ANOVA or $t$-tests

Note: means with same superscript letter are not significantly different

among all race/ethnic groups except those in the "other/mixed" category.

Low chronic exposure to iAs has been associated with cardiovascular disease, [37] diabetes, [15] and sleep disturbance, [38] which are all diseases known to have oxidative stress as a key mechanism [39]. It is through increases in oxidative stress that iAs exposure may be linked to these common conditions although the exact mechanisms are unknown [40-44]. Arsenic, even at low concentrations can also activate nuclear factor (NF)-kappaB, a protein complex that controls transcription of DNA, cytokine production and cell survival [45]. Activation of NF-kappaB has been noted as a connection between oxidative stress and chronic diseases such as type 2 diabetes and insulin resistance $[46,47]$. Arsenic methylation occurs in the liver, yet it is unknown how much arsenic metabolites need to accumulate in the liver to produce an ill effect [13]. It is this link that needs to be further studied to elucidate arsenic's role in NAFLD and other chronic liver diseases.
We found a positive association between high iAs and high ALT levels, an association that was significant and strongest among Mexican Americans in the U.S. It has been shown previously that low doses of arsenic are associated with rice and poultry consumption in the U.S. $[17,23,48,49]$ Rice effectively absorbs arsenic from the soil. It is also commonly consumed by some cultures including Hispanics, African-American, and Asian cultures [49]. Although we did not assess diet, we found higher inorganic arsenic concentrations in these racial groups. Previous studies have shown arsenic levels to be higher in children that consume rice, including studies that analylzed data from the NHANES [23, 48].

This study had several important strengths. It was the first known study to examine the association between iAs exposure and NAFLD risk among humans. Use of a large, national sample with demographic and anthropometric data as well as biological samples allowed us to control for important potential confounders in our examination of this association. The availability of race/ethnicity data provided a means to assess the extent to which it modifies the association between iAs and NAFLD risk. The availability of data on high alcohol use and hepatitis $B$ and $C$ infection allowed us to exclude those with other known or suspected liver disease. Further, all data was collected using trained staff and standardized protocols. The laboratory methods used were of the highest quality with both arsenic and ALT measured using established in Center for Disease Control and Prevention (CDC) verified labs in the NHANES study reducing possibility of measurement error. While there were a number of samples with levels below the level of detection this had no impact on our analysis as arsenic exposure was examined in quartiles.

This study also had some limitations that must be noted. First, as this is a cross-sectional study, temporality cannot be established so the results cannot be taken to indicate causality. Secondly, a definitive diagnosis of NAFLD requires a liver biopsy, which was not available (or feasible) for this national sample. Therefore, we used ALT levels as a surrogate marker. While ALT is commonly used as a screening tool for NAFLD, there are other conditions that could contribute to a high ALT including chronic hepatitis and excessive alcohol consumption. To minimize bias due to misclassification, those with these conditions were excluded from the sample. Finally, the sample sizes in some of our subgroup analyses were very small, particularly when stratifying by obesity status, which subjects those results to a greater sampling error bias. High relative standard errors, which are reflected in wide confidence intervals, suggest that the comparison being made may not be reliable or representative. To address this, we have presented the sample size for all subgroups as well as the 
Table 4 Adjusted odds ratio of elevated alanine aminotransferase (ALT) levels with increasing inorganic arsenic concentrations by race/ethnicity and by weight status

\begin{tabular}{|c|c|c|c|c|c|c|c|c|c|}
\hline \multirow[t]{3}{*}{ Model } & \multirow[b]{3}{*}{$N$} & \multicolumn{8}{|c|}{ Quartile of Inorganic Arsenic [point estimate (95\% Confidence Intervals)] } \\
\hline & & \multicolumn{2}{|l|}{1 st } & \multicolumn{2}{|l|}{ 2nd } & \multicolumn{2}{|l|}{$3 r d$} & \multicolumn{2}{|l|}{4 th } \\
\hline & & 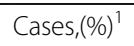 & $\overline{\mathrm{aOR}}$ & $\overline{\text { Cases }(\%)^{1}}$ & $\overline{\mathrm{aOR}(95 \% \mathrm{Cl})}$ & $\overline{\left.\text { Cases, }_{(} \%\right)^{1}}$ & $\mathrm{aOR}(95 \% \mathrm{Cl})$ & $\overline{\left.\text { Cases, }_{(} \%\right)^{1}}$ & aOR $(95 \% \mathrm{Cl})$ \\
\hline$\overline{\mathrm{All}^{2}}$ & 8518 & $506(28 \%)$ & Ref & $644(31 \%)$ & $1.2(0.7,1.9)$ & $736(33 \%)$ & $1.6(1.0,2.8)$ & $827(35 \%)$ & $2.0(1.2,3.4)$ \\
\hline \multicolumn{10}{|l|}{ Race/Ethnicity ${ }^{3}$} \\
\hline Non-Hispanic White & 3579 & $325(30 \%)$ & Ref & $310(32 \%)$ & $1.1(0.9,1.4)$ & $262(32 \%)$ & $1.0(0.8,1.3)$ & $261(37 \%)$ & $1.4(1.1,1.8)$ \\
\hline Non-Hispanic Black & 1828 & 47 (17\%) & Ref & $92(21 \%)$ & $1.2(0.8,1.7)$ & $127(25 \%)$ & $1.4(0.9,2.2)$ & $153(25 \%)$ & $1.4(0.9,2.1)$ \\
\hline Mexican Americans & 1624 & 74 (30\%) & Ref & $150(35 \%)$ & $1.5(1.0,2.2)$ & 202 (39\%) & $1.7(1.1,2.6)$ & 191 (44\%) & $2.0(1.3,3.1)$ \\
\hline Other Hispanics & 770 & $33(40 \%)$ & Ref & $61(39 \%)$ & $0.7(0.3,1.3)$ & $90(41 \%)$ & $0.9(0.5,1.7)$ & $112(36 \%)$ & $0.6(0.3,1.1)$ \\
\hline Other or Mixed & 717 & $27(24 \%)$ & Ref & $31(27 \%)$ & $1.1(0.5,2.3)$ & 55 (34\%) & $1.7(0.7,4.2)$ & $110(34 \%)$ & $1.7(0.8,3.7)$ \\
\hline \multicolumn{10}{|l|}{ BMI Weight Group ${ }^{4}$} \\
\hline Underweight/Normal & 3319 & 146 (19\%) & Ref & $144(7 \%)$ & $0.9(0.7,1.3)$ & $168(20 \%)$ & $1.1(0.8,1.5)$ & $183(21 \%)$ & $1.34(1.0,1.8)$ \\
\hline Overweight & 2480 & 159 (31\%) & Ref & $183(31 \%)$ & $1.0(0.8,1.5)$ & $213(33 \%)$ & $0.98(0.7,1.4)$ & $262(36 \%)$ & $1.31(0.9,1.9)$ \\
\hline Obese & 2719 & 201 (39\%) & Ref & $317(46 \%)$ & $1.4(1.0,1.9)$ & $355(48 \%)$ & $1.3(1.0,1.8)$ & $382(48 \%)$ & $1.50(1.1,2.0)$ \\
\hline \multicolumn{10}{|l|}{ Obese Only ${ }^{4}$} \\
\hline Non-Hispanic White & 1067 & 134 (44\%) & Ref & $139(47 \%)$ & $1.3(0.9,2.1)$ & $129(50 \%)$ & $1.3(0.8,2.0)$ & 108 (50\%) & $1.5(1.0,2.2)$ \\
\hline Non-Hispanic Black & 726 & $17(18 \%)$ & Ref & $57(33 \%)$ & $1.7(0.9,3.1)$ & $73(37 \%)$ & $2.0(1.0,3.9)$ & 95 (37\%) & $2.0(1.1,3.8)$ \\
\hline Mexican Americans & 554 & $29(44 \%)$ & Ref & $82(57 \%)$ & $1.9(1.0,3.5)$ & $102(53 \%)$ & $1.4(0.7,2.9)$ & 94 (61\%) & $1.9(1.0,3.5)$ \\
\hline Other Hispanics & 255 & $7(37 \%)$ & Ref & $31(57 \%)$ & $2.8(0.6,13.4)$ & $40(57 \%)$ & $3.3(0.8,13.9)$ & 55 (49\%) & $1.9(0.5,7.5)$ \\
\hline Other or Mixed & 117 & $14(50 \%)$ & Ref & $8(44 \%)$ & $0.4(0.1,2.2)$ & $11(50 \%)$ & $0.5(0.1,2.6)$ & 30 (61\%) & $0.9(0.3,3.3)$ \\
\hline
\end{tabular}

All model adjusted for age, survey cycle, gender, PIR, race/ethnicity, BMI Weight status, and interactions (race/ethnicity*iAS, BMI weight status*iAS)

$1 \%$ cases = \# with elevated ALT divided by the total in the arsenic exposure quartile + race/ethnic or weight category subgroup

${ }^{2}$ Adjusted for age, survey cycle, gender, PIR, BMI Weight status, and race/ethnicity

${ }^{3}$ Adjusted for age, survey cycle, gender, PIR, and $B M I$ Weight status

${ }^{4}$ Adjusted for age, survey cycle, gender, PIR, and race/ethnicity

Note: High blood-ALT levels were defined as $>25 \mathrm{IU} / \mathrm{L}$ for boys $\leq 17$ years and $>22 \mathrm{IU} / \mathrm{L}$ for girls $\leq 17$ years. In adults, high ALT was defined $>30 \mathrm{IU} / \mathrm{L}$

in males and $>19 \mathrm{IU} / \mathrm{L}$ in females

confidence intervals for all estimates to make the level of uncertainty around estimates clear to the reader.

\section{Conclusion}

The results of this study demonstrate that there is a positive association between inorganic arsenic exposure and elevated ALT in humans of all weight categories, and that risk is highest among Mexican Americans and those obese, regardless of race/ethnicity. Further research is needed to confirm this association in subjects with confirmed NAFLD, to identify the biological mechanisms involved, and to develop strategies for ameliorating and reducing exposure to arsenic.

\section{Abbreviations}

ALT: Alanine aminotransferase; Anti-HBc: Hepatitis B core antibody; Anti-HCV: Hepatitis C antibody; aOR: Adjusted odds ratio; BMI: Body mass index; iAs: Inorganic arsenic; ICP-DRC-MS: Inductively coupled-plasma dynamic reaction cell-mass spectrometry; IQR: Interquartile range; LLOD: Lower limit of detection; NAFLD: Nonalcoholic fatty liver disease; NHANES: National Health and Nutrition Examination Survey; PIR: Poverty income ratio

\section{Funding}

CM- NIH-NIEHS P01 ES022832, P30 ES019776, US EPA grant RD83544201, MV- R21 HD0809056-01, MV, EN, JF - 1U2CES026560-01.

\section{Availability of data and materials}

The datasets used and/or analyzed during the current study are available from https://www.cdc.gov/nchs/nhanes/nhanes_questionnaires.htm

\section{Authors' contributions}

JKF designed study, interpreted results, drafted the manuscript. EN completed data analysis and drafted methods section. JF supervised data analysis and interpreted results. JW designed study, interpreted results. MV designed study. All authors read, edited and approved the final manuscript.

\section{Ethics approval and consent to participate}

The consent form was signed by participants in the survey, and participants consented to storing specimens of their blood for future research. The CDC/ NCHS Ethics Review Board (ERB) approved the NHANES study and gave approval for public dissemination.

Consent for publication

Non applicable.

Competing interests

The authors declare that they have no competing interests.

\section{Publisher's Note}

Springer Nature remains neutral with regard to jurisdictional claims in published maps and institutional affiliations. 


\section{Author details}

'Department of Pediatrics, Emory University School of Medicine, Atlanta, GA, USA. ${ }^{2}$ Department of Biostatistics and Bioinformatics, Rollins School of Public Health, Emory University, Atlanta, GA, USA. ${ }^{3}$ Department of Environmental Health, Rollins School of Public Health, Emory University, Atlanta, GA, USA. ${ }^{4}$ Wellness Department, Children's Healthcare of Atlanta, Atlanta, GA, USA.

\section{Received: 5 July 2017 Accepted: 28 December 2017}

\section{Published online: 15 January 2018}

\section{References}

1. Welsh JA, Karpen S, Vos MB. Increasing prevalence of nonalcoholic fatty liver disease among United States adolescents, 1988-1994 to 2007-2010. J Pedatr. 2013;162(3):496-500.

2. Le MH, Devaki P, Ha NB, Jun DW, Te HS, Cheung RC, et al. Prevalence of non-alcoholic fatty liver disease and risk factors for advanced fibrosis and mortality in the United States. PLoS One. 2017;12(3):e0173499.

3. Fleischman MW, Budoff M, Zeb I, Li D, Foster T. NAFLD prevalence differs among hispanic subgroups: the multi-ethnic study of atherosclerosis. World J Gastroenterol. 2014;20(17):4987-93.

4. Yki-Jarvinen H. Non-alcoholic fatty liver disease as a cause and a consequence of metabolic syndrome. lancet Diabetes endocrinol. 2014; 2(11):901-10.

5. Romeo S, Kozlitina J, Xing C, et al. Genetic variation in PNPLA3 confers susceptibility to nonalcoholic fatty liver disease. Nat Genet. 2008;40(12):1461-5.

6. Wagenknecht LE, Palmer ND, Bowden DW, Rotter JI, Norris JM, Ziegler J, et al. Association of PNPLA3 with non-alcoholic fatty liver disease in a minority cohort: the insulin resistance atherosclerosis family study. Liver Int. 2011:31(3):412-6.

7. Hernaez R, McLean J, Lazo M, Brancati FL, Hirschhorn JN, Borecki IB, et al. Association between variants in or near PNPLA3, GCKR, and PPP1R3B with ultrasound-defined steatosis based on data from the third National Health and nutrition examination survey. Clin Gastroenterol Hepatol. 2013;11(9): 1183-1190.e1182.

8. Tarantino G, Capone D, Finelli C. Exposure to ambient air particulate matter and non-alcoholic fatty liver disease. World J Gastroenterol. 2013;19(25):3951-6

9. Cave M, Appana S, Patel M, Falkner KC, McClain CJ, Brock G. Polychlorinated biphenyls, lead, and mercury are associated with liver disease in American adults: NHANES 2003-2004. Environ Health Perspect. 2010;118(12):1735-42.

10. Kimura T, Deshpande GA, Urayama KY, Masuda K, Fukui T, Matsuyama Y. Association of weight gain since age 20 with non-alcoholic fatty liver disease in normal weight individuals. J Gastroenterol Hepatol. 2015;30(5):909-17.

11. Lin YC, Lian IB, Kor CT, Chang CC, PY S, Chang WT, et al. Association between soil heavy metals and fatty liver disease in men in Taiwan: a cross sectional study. BMJ Open. 2017;7(1):e014215.

12. Park SK, Peng Q, Bielak LF, Silver KD, Peyser PA, Mitchell BD. Arsenic exposure is associated with diminished insulin sensitivity in non-diabetic Amish adults. Diabetes Metab Res Rev. 2016;32(6):565-71.

13. Tseng $\mathrm{CH}$. The potential biological mechanisms of arsenic-induced diabetes mellitus. Toxicol Appl Pharmacol. 2004;197(2):67-83.

14. Lin HC, Huang YK, Shiue HS, Chen LS, Choy CS, Huang SR, et al. Arsenic methylation capacity and obesity are associated with insulin resistance in obese children and adolescents. Food Chem Toxicol. 2014;74:60-7.

15. Rhee SY, Hwang YC, Woo JT, Chin SO, Chon S, Kim YS. Arsenic exposure and prevalence of diabetes mellitus in Korean adults. J Korean Med Sci. 2013;28(6):861-8.

16. Cubadda F, Jackson BP, Cottingham KL, Van Horne YO, Kurzius-Spencer M. Human exposure to dietary inorganic arsenic and other arsenic species: state of knowledge, gaps and uncertainties. Sci Total Environ. 2017;579:1228-39.

17. Nigra AE, Nachman KE, Love DC, Grau-Perez M, Navas-Acien A. Poultry consumption and arsenic exposure in the U.S. population. Environ Health Perspect. 2017;125(3):370-7.

18. Signes-Pastor AJ, Woodside JV, McMullan P, Mullan K, Carey M, Karagas MR, et al. Levels of infants' urinary arsenic metabolites related to formula feeding and weaning with rice products exceeding the EU inorganic arsenic standard. PLoS One. 2017;12(5):e0176923.

19. FDA, editor. FDA announces pending withdrawal of approval of nitarsone. Arlington: FDA; 2015

20. Adams SV, Barrick B, Christopher EP, Shafer MM, Song X, Vilchis H, et al. Urinary heavy metals in Hispanics 40-85 years old in Dona Ana County, New Mexico. Arch Environ Occup Health. 2016;71(6):338-46.
21. Awata H, Linder S, Mitchell LE, Delclos GL. Association of Dietary Intake and Biomarker Levels of arsenic, cadmium, lead, and mercury among Asian populations in the United States: NHANES 2011-2012. Environ Health Perspect. 2017;125(3):314-23.

22. Wu H, Grandjean P, FB H, Sun Q. Consumption of white Rice and Brown Rice and urinary inorganic arsenic concentration. Epidemiology. 2015;26(6):e65-7.

23. Davis MA, Mackenzie TA, Cottingham KL, Gilbert-Diamond D, Punshon T, Karagas MR. Rice consumption and urinary arsenic concentrations in U.S. children. Environ Health Perspect. 2012;120(10):1418-24.

24. Straub AC, Stolz DB, Ross MA, Hernandez-Zavala A, Soucy NV, Klei LR, et al. Arsenic stimulates sinusoidal endothelial cell capillarization and vessel remodeling in mouse liver. Hepatology. 2007;45(1):205-12.

25. Ditzel EJ, Li H, Foy CE, Perrera AB, Parker P, Renquist BJ, et al. Altered hepatic transport by fetal Arsenite exposure in diet-induced fatty liver disease. J Biochem Mol Toxicol. 2016;30(7):321-30.

26. Tan M, Schmidt RH, Beier JI, Watson WH, Zhong H, States JC, et al. Chronic subhepatotoxic exposure to arsenic enhances hepatic injury caused by high fat diet in mice. Toxicol Appl Pharmacol. 2011;257(3):356-64.

27. National Research Council (US) Subcommittee on Arsenic in Drinking Water. Arsenic in drinking water. Washington DC: National Academies Press; 1999.

28. Biswas A, Deb D, Ghose A, Du Laing G, De Neve J, Santra SC, et al. Dietary arsenic consumption and urine arsenic in an endemic population: response to improvement of drinking water quality in a 2-year consecutive study. Environ Sci Pollut Res Int. 2014;21(1):609-19.

29. Cardenas A, Smit E, Houseman EA, Kerkvliet NI, Bethel JW, Kile ML. Arsenic exposure and prevalence of the varicella zoster virus in the United States: NHANES (2003-2004 and 2009-2010). Environ Health Perspect 2015;123(6):590-596

30. Peng Q, Harlow SD, Park SK. Urinary arsenic and insulin resistance in US adolescents. Int J Hyg Environ Health. 2015;218(4):407-13.

31. O'Brien KM, Upson K, Cook NR, Weinberg CR. Environmental Chemicals in Urine and Blood: improving methods for Creatinine and lipid adjustment. Environ Health Perspect. 2016;124(2):220-7.

32. Schwimmer JB, Dunn W, Norman GJ, Pardee PE, Middleton MS, Kerkar N, et al. SAFETY study: alanine aminotransferase cutoff values are set too high for reliable detection of pediatric chronic liver disease. Gastroenterology. 2010;138(4):1364.e1361-2.

33. Martin-Rodriguez JL, Gonzalez-Cantero J, Gonzalez-Cantero A, Arrebola JP, Gonzalez-Calvin JL. Diagnostic accuracy of serum alanine aminotransferase as biomarker for nonalcoholic fatty liver disease and insulin resistance in healthy subjects, using 3T MR spectroscopy. Medicine (Baltimore). 2017;96(17):e6770.

34. Verma S, Jensen D, Hart J, Mohanty SR. Predictive value of ALT levels for non-alcoholic steatohepatitis (NASH) and advanced fibrosis in non-alcoholic fatty liver disease (NAFLD). Liver Int 2013;33(9):1398-1405.

35. Prati D, Taioli E, Zanella A, Della Torre E, Butelli S, Del Vecchio E, et al. Updated definitions of healthy ranges for serum alanine aminotransferase levels. Ann Intern Med. 2002;137(1):1-10.

36. Bailey RL, Akabas SR, Paxson EE, Thuppal SV, Saklani S, Tucker KL. Total usual intake of shortfall nutrients varies with poverty among US adults. J Nutr Educ Behav. 2017:49:639-46.

37. Nong Q, Zhang Y, Guallar E, Zhong Q. Arsenic exposure and predicted 10year atherosclerotic cardiovascular risk using the pooled cohort equations in U.S. hypertensive adults. Int J Environ Res Public Health. 2016;13(11)e1093.

38. Shiue I. Urinary arsenic, pesticides, heavy metals, phthalates, polyaromatic hydrocarbons, and polyfluoroalkyl compounds are associated with sleep troubles in adults: USA NHANES, 2005-2006. Environ Sci Pollut Res Int. 2017;24(3):3108-16.

39. Siti HN, Kamisah Y, Kamsiah J. The role of oxidative stress, antioxidants and vascular inflammation in cardiovascular disease (a review). Vasc Pharmacol 2015:71:40-56.

40. Henkler F, Brinkmann J, Luch A. The role of oxidative stress in carcinogenesis induced by metals and xenobiotics. Cancers. 2010;2(2):376-96.

41. Yamanaka K, Hoshino M, Okamoto M, Sawamura R, Hasegawa A, Okada S. Induction of DNA damage by dimethylarsine, a metabolite of inorganic arsenics, is for the major part likely due to its peroxyl radical. Biochem Biophys Res Commun. 1990;168(1):58-64.

42. De Vizcaya-Ruiz A, Barbier O, Ruiz-Ramos R, Cebrian ME. Biomarkers of oxidative stress and damage in human populations exposed to arsenic. Mutat Res. 2009:674(1-2):85-92.

43. Choudhury S, Ghosh S, Mukherjee S, Gupta P, Bhattacharya S, Adhikary A, et al. Pomegranate protects against arsenic-induced p53-dependent ROS-mediated inflammation and apoptosis in liver cells. J Nutr Biochem. 2016;38:25-40. 
44. Padmaja Divya S, Pratheeshkumar P, Son YO, Vinod Roy R, Andrew Hitron J, Kim D, et al. Arsenic induces insulin resistance in mouse Adipocytes and Myotubes via oxidative stress-regulated mitochondrial Sirt3-FOXO3a signaling pathway. Toxicol Sci. 2015;146(2):290-300.

45. Cao S, Liu S, Wang F, Liu J, Li M, Wang C, et al. DMA(V) in drinking water activated NF-kappaB signal pathway and increased TGF-beta and IL-1 beta expressions in bladder epithelial cells of rats. Mediat Inflamm 2015;2015:790652

46. Katsuki A, Sumida Y, Urakawa H, Gabazza EC, Murashima S, Nakatani K, et al. Increased oxidative stress is associated with serum levels of triglyceride, insulin resistance, and hyperinsulinemia in Japanese metabolically obese, normal-weight men. Diabetes Care. 2004;27:631-2.

47. Haber CA, Lam TK, Yu Z, Gupta N, Goh T, Bogdanovic E, et al. Nacetylcysteine and taurine prevent hyperglycemia-induced insulin resistance in vivo: possible role of oxidative stress. Am J Physiol Endocrinol Metab. 2003;285:E744-53.

48. deCastro BR, Caldwell KL, Jones RL, Blount BC, Pan Y, Ward C, et al. Dietary sources of methylated arsenic species in urine of the United States population, NHANES 2003-2010. PLoS One. 2014;9(9):e108098.

49. Wei Y, Zhu J, Nguyen A. Rice consumption and urinary concentrations of arsenic in US adults. Int J Environ Health Res. 2014;24(5):459-70

\section{Submit your next manuscript to BioMed Central and we will help you at every step:}

- We accept pre-submission inquiries

- Our selector tool helps you to find the most relevant journal

- We provide round the clock customer support

- Convenient online submission

- Thorough peer review

- Inclusion in PubMed and all major indexing services

- Maximum visibility for your research

Submit your manuscript at www.biomedcentral.com/submit

) Biomed Central 